This article is from the

July-August 2014 issue of

Cereal Chemistry

published by

AACC International, Inc.

For more information on this and other topics

related to cereal science,

we invite you to visit the $A A C C I$ website at

www.aaccnet.org

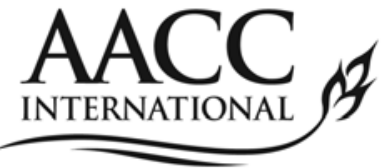

Advancing grain science worldwide 


\title{
Measurement and Comparison of Glass Transition and Sticky Point Temperatures of Distillers Dried Grains with Solubles (DDGS) with Varying Condensed Distillers Solubles (CDS) and Drying Temperature Levels
}

\author{
Rumela Bhadra, ${ }^{1}$ Kurt A. Rosentrater, ${ }^{2,3}$ and K. Muthukumarappan ${ }^{4}$
}

\begin{abstract}
Distillers dried grains with solubles (DDGS) is the main coproduct of the U.S. fuel ethanol industry and has significantly impacted the livestock feed markets in recent years. Particle agglomeration and subsequent flowability problems during storage and transport are often a hindrance, a nuisance, and expensive. This paper aims at characterizing the glass transition $\left(T_{\mathrm{g}}\right)$ and sticky point $\left(T_{\mathrm{s}}\right)$ temperatures of DDGS samples prepared with varying condensed distillers solubles (CDS) levels (10, 15, and 20\%, wb), drying temperatures $\left(100,200\right.$, and $\left.300^{\circ} \mathrm{C}\right)$, and moisture contents $(0,10$, and $20 \%, \mathrm{db})$, and it discusses implications on DDGS flowability behavior. Distillers wet grains were combined with specified levels of CDS and dried in a convection-style laboratory oven to produce DDGS.
\end{abstract}

ABSTRACT

Cereal Chem. 91(4):406-413
Subsequently, predetermined amounts of water were added to the DDGS to achieve desired moisture content levels. To determine $T_{\mathrm{g}}\left({ }^{\circ} \mathrm{C}\right)$, a differential scanning calorimeter was used, whereas $T_{\mathrm{s}}\left({ }^{\circ} \mathrm{C}\right)$ was determined through a novel technique with a rheometer. Results indicated high correlations between observed $T_{\mathrm{s}}$ and observed $T_{\mathrm{g}}\left(R^{2}=0.87\right)$ data for DDGS samples. Also, the empirical model for predicted $T_{\mathrm{g}}=f$ (drying temperature, CDS level, and moisture content) based on the Gordon-Taylor model showed favorable $R^{2}(0.74)$. Stickiness of DDGS increased with an increase in moisture content, indicating flow problems resulting from moisture. It was found that drying temperatures and CDS levels each had significant effects on $T_{\mathrm{g}}$ and $T_{\mathrm{s}}$ as well.
Distillers dried grains with solubles (DDGS) is the primary coproduct from the corn-based fuel ethanol industry, which is mainly from dry-grind ethanol production plants across the Midwestern United States. It is commonly used as livestock feed for cattle, swine, and poultry. DDGS typically contains $86-93 \%(\mathrm{db})$ dry matter, $26-34 \%(\mathrm{db})$ crude protein, $3-13 \%(\mathrm{db})$ fat, and essential amino acids such as methionine, leucine, arginine, and threonine (Speihs et al 2002; Rosentrater and Muthukumarappan 2006). There has been enormous growth in the bioethanol industry in the last decade because of strong interest in alternative fuels, and therefore there is now substantial DDGS production. The production of DDGS is projected to have grown to nearly 40 million metric tons during 2013.

Like many agricultural and food materials, DDGS is hygroscopic in nature (i.e., it can absorb moisture from the surrounding atmosphere). Thus, DDGS particles may tend to agglomerate to form solidified masses (i.e., caking) by absorbing water or because of temperature differences. Caking, or hardening, of DDGS leads to difficulties during unloading from rail cars, bins, and other storage vessels, and it can result in economic losses to break up the agglomerates and discharge the storage vessels (Rock and Schwedes 2005). Stickiness in particles (or the caking phenomenon) causes poor flowability in the material and, thus, makes it less efficient to handle during distribution and storage. An understanding of properties affecting stickiness is crucial in defining appropriate processing, handling, and storage conditions for the material (Lazar et al 1956; Downton et al 1982; Wallack and King 1988).

Stickiness is often a problem that can impact both the quality of the product and manufacturing operations, and it can lead to equip-

\footnotetext{
* The $e$-Xtra logo stands for "electronic extra" and indicates that Figures 1, 2, 5, and 6 appear in color online.

${ }^{1}$ Postdoctoral research associate, Department of Agricultural and Biosystems Engineering, Kansas State University, Manhattan, KS, U.S.A.

${ }^{2}$ Assistant professor, Department of Agricultural and Biosystems Engineering, Iowa State University, Ames, IA, U.S.A.

${ }^{3}$ Corresponding author. Phone: (515) 294-4019. Fax: (515) 294-6633. E-mail: karosent@iastate.edu

${ }^{4}$ Professor, Department of Agricultural and Biosystems Engineering, South Dakota State University, Brookings, SD, U.S.A.
}

http://dx.doi.org/10.1094/CCHEM-05-13-0106-R

(c) 2014 AACC International, Inc. ment wear and increased costs. Some have attributed it to adhesive and cohesive properties, effects of external factors, or the viscosity and viscoelasticity of the materials (Adhikari et al 2001). The cereal industry, the confectionary industry (because of sucrose or other sugar-based syrups), and the dairy industry (because of frequent caking of milk powders caused by milk proteins) (Hegg et al 1985) face stickiness issues in bulk handling. Some of the key factors that cause agglomeration of food and biological powders are viscosity (Simatos and Blond 1993), for which the governing model is the Williams-Landel-Ferry model (1955), plasticization of water (Adhikari et al 2001), temperature (Roos and Karel 1990), compaction because of load (Teunou et al 1999), and hygroscopic biological molecules such as glucose, fructose, and protein (Netto et al 1998).

Glass Transition Temperature $\left(\boldsymbol{T}_{\mathrm{g}},{ }^{\circ} \mathrm{C}\right)$. Spray-dried or rotary drum dried products such as milk powders and fruit powders are amorphous solids. They are produced by a rapid drying process so that the food molecules do not have much time to align themselves and become crystalline. For DDGS, previous work has reported that the temperature of any typical drying operation ranges from 300 to $1,000^{\circ} \mathrm{F}$, and the time taken to produce the dried DDGS is only a few seconds (Bhadra et al 2011a, 2011b). Therefore, like other food and milk powders, DDGS also has a high drying temperature and short drying time and, thus, forms an amorphous solid. The amorphous solid is often referred to as glass, a metastable supercooled liquid, with the typical range of viscosities of about $10^{12} \mathrm{~Pa} \cdot \mathrm{s}$ (Adhikari et al 2001). When an amorphous solid is heated, it undergoes a second-order phase transition known as the glass transition, in which the glasslike state assumes a more liquid form (rubbery) with lower viscosities of $10^{6}-10^{8}$ Pa.s. Stickiness, caking, or the agglomeration of the powder are mostly associated with this rubbery phase (Downton et al 1982). The glasslike state will first be converted to a glass-rubbery phase transition state exactly at the glass transition temperature $\left(T_{\mathrm{g}}\right)$. After the phase transition period, the molecules will eventually be converted to crystals, whereas further heating of the product at increased temperature will melt the food powder. $T_{\mathrm{g}}$ is characterized by a change in the apparent specific heat capacity. This change takes place endothermically and is easily detected with a differential scanning calorimeter (DSC) (Roos and Karel 1990). $T_{\mathrm{g}}$ is affected by various factors, especially the composition of the material, molecular weight, and presence of plasticizers. Plasticiz- 
ers such as water can lower the $T_{\mathrm{g}}\left({ }^{\circ} \mathrm{C}\right)$ by diffusion of water molecules in the amorphous materials.

Sticky Point Temperature $\left(\boldsymbol{T}_{\mathrm{s}},{ }^{\circ} \mathrm{C}\right)$. Researchers developed a way to measure the sticky point temperature $\left(T_{\mathrm{s}},{ }^{\circ} \mathrm{C}\right)$, aside from the most popular method of measuring $T_{\mathrm{g}}$, for assessing stickiness in powders. $T_{\mathrm{s}}$ is defined as the given combination of temperature and moisture content at which a mass of powdery material resists movement and no longer flows freely. The moisture content-temperature graph is also known as the stickiness curve. $T_{\mathrm{s}}$ decreases as the moisture content increases, indicating more difficult flow behavior in the powders.

The sticky point temperature measurement developed by Lazar et al (1956) was later used by several other researchers (Downton et al 1982; Wallack and King 1988). In the experimental setup for Lazar et al (1956), a sample in a glass tube was stirred manually. Figure 1 shows the concepts of the sticky region and the sticky point temperature $\left(T_{\mathrm{s}}\right)$ curve; more details on the sticky point method, the stickiness curve, the experimental setup, and the procedures can be found in Lazar et al (1956), Papadakis and Bahu (1992), and Wallack and King (1988). However, the traditional setup (Lazar et al 1956) and procedure of measuring $T_{\mathrm{s}}$ were modified several times by several authors (Pasley et al 1995; Hennigs et al 2001; Chegini and Ghobadian 2007). There are peer-reviewed articles comparing $T_{\mathrm{g}}$ with $T_{\mathrm{s}}$ and elaborately describing the phenomenon of stickiness or caking in food powders (Downton et al 1982; Chuy and Labuza 1994; Jaya and Das 2007).

With respect to the stickiness and flowability issues in DDGS with varying condensed distillers solubles (CDS) and moisture content, some work has been done with Carr (1965) and Jenike (1964) shear test properties (Ganesan et al 2007a, 2007b, 2008a, 2008b; Bhadra et al 2009a, 2009b). To date, only Ganesan and Rosentrater (2007) reported that $T_{\mathrm{g}}$ was correlated to stickiness and flowability issues of DDGS. However, this study was performed on a small scale, and more information is required to fully understand and quantify the cause of flowability problems in DDGS. Ganesan and Rosentrater (2007) reported $T_{\mathrm{g}}$ values for traditional DDGS, reduced-fat DDGS, dewaxed DDGS, and distillers dried grains (without solubles), but they did not perform any mathematical modeling for $T_{\mathrm{g}}$. Also, no experiments were done to investigate $T_{\mathrm{s}}$ for DDGS samples and to correlate the results with DDGS caking problems.

Thus, the main objectives of this study were 1) to evaluate $T_{\mathrm{g}}$ and $T_{\mathrm{s}}$ for DDGS samples prepared under laboratory conditions with varying $\operatorname{CDS}(10,15$, and $20 \%$, wb), drying temperature $\left(100,200\right.$, and $\left.300^{\circ} \mathrm{C}\right)$, and moisture content $(0,10$, and $20 \%$, db) levels; 2) to develop an overall model based on varying drying temperature, CDS, and moisture content levels for predicting $T_{\mathrm{g}}$ (based on the Gordon-Taylor [1952] equation) and $T_{\mathrm{s}}$ (based on nonlinear regression analysis); and 3) to compare observed $T_{\mathrm{g}}$ and observed $T_{\mathrm{s}}$ values and examine the correlation between the corresponding dataset.

Such approaches have not yet been reported for DDGS, and they eventually may provide an understanding about how DDGS flowability and stickiness problems often occur.

\section{MATERIALS AND METHODS}

Sample Collection. Samples of distillers wet grains and CDS were collected from a commercial ethanol plant in South Dakota and were stored under frozen conditions $\left(-10 \pm 1^{\circ} \mathrm{C}\right)$ until needed. After thawing for $24 \mathrm{~h}, \mathrm{CDS}$ was added to the distillers wet grains at levels of 10,15 , and $20 \%$ (wb) and then mixed thoroughly in a mixer (model D300, Hobart, Troy, OH, U.S.A.) for $5 \mathrm{~min}$.

Sample Preparation. Combined samples $(\approx 300 \mathrm{~g})$ were spread uniformly on a thin steel plate with the dimensions of $38 \times 27 \times$ $1 \mathrm{~cm}$ and were dried in a laboratory-scale (model 838F, Fisher Scientific, Pittsburg, PA, U.S.A.) oven. The drying was done at three selected temperatures $\left(100,200\right.$, and $\left.300^{\circ} \mathrm{C}\right)$. Temperature range selection was based on interviews and discussions with industry experts and upon our previous drying studies (Bhadra et al 2011a, 2011b). For each temperature and CDS combination, the drying was done for a specified time limit to reduce all the experimental samples to $8 \%(\mathrm{db})$ moisture content, so that we had a common baseline in all the samples for moisture content to eliminate its possible influence on the measured properties. Commercial DDGS samples were found to be around $8 \%(\mathrm{db})$ moisture content. We had to dry each treatment combination with a different drying time so that the target value of $8 \%(\mathrm{db})$ moisture content was achieved. These dried samples were used partly to measure flow properties, as reported in Bhadra et al (2012b), and the other half were mildly dried in the oven for an additional $8 \mathrm{~h}$ at $50^{\circ} \mathrm{C}$ to reduce the moisture content to $0 \%(\mathrm{db})$, so that specific levels of water could be added to achieve the desired final moisture contents of 10 and $20 \%(\mathrm{db})$. Thus, in total we had 54 (three drying temperatures $\times$ three CDS levels $\times$ three final moisture contents $\times$ two replicate preparations) experimental runs for $T_{\mathrm{g}}$ and $T_{\mathrm{s}}$ measurements, and we implemented a full factorial randomized experimental design.

Measurement and Modeling of Glass Transition Temperature $\left(\boldsymbol{T}_{\mathrm{g}},{ }^{\circ} \mathbf{C}\right) . D S C$. The glass transition temperature $\left(T_{\mathrm{g}}\right)$ of the DDGS samples was evaluated with a DSC (DSC822, Mettler Toledo, Schwerzenbach, Switzerland). Sample crucibles of $100 \mu \mathrm{L}$ were subjected to a heating range of -20 to $100^{\circ} \mathrm{C}$ with a heating rate of $5^{\circ} \mathrm{C} / \mathrm{min}$. These conditions were based on the previous studies of DDGS by Ganesan and Rosentrater (2007). An empty aluminum crucible of $100 \mu \mathrm{L}$ was the reference cell, and both the sample and reference cells were placed on their respective thermocouple sensors in the DSC. Liquid nitrogen was used as a dry gas to cool the furnace, and helium was used as the carrier gas or purge gas at $50 \mathrm{~mL} / \mathrm{min}$. $T_{\mathrm{g}}$ is indicated by the sudden change in the heat flow as temperature increases, and it was reported by using the STARe software provided with the DSC analyzer. Two replications for each run were carried out for each sample combination.

Modeling of Glass Transition Temperature. A $T_{\mathrm{g}}$ prediction model for mixtures comprising amorphous polymers was first proposed by Gordon and Taylor (1952), which is mathematically described as follows:

$$
T_{g}=\frac{X_{s} T_{g s}+K X_{w} T_{g w}}{X_{s}+K X_{w}}
$$

where $T_{\mathrm{g}}$ is the glass transition temperature of the mixture $\left({ }^{\circ} \mathrm{C}\right)$; $T_{\mathrm{gs}}$ and $T_{\mathrm{gw}}$ are the glass transition of the solid (in this case, it

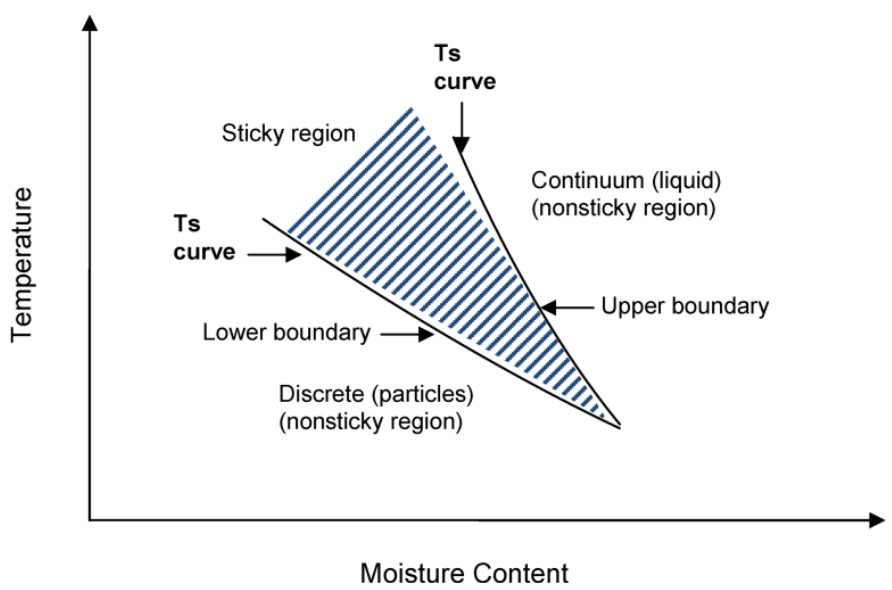

Fig. 1. Typical sticky region and sticky point temperature $\left(T_{\mathrm{s}}\right)$ curves, based on Kudra (2003). For this study, the nonsticky region lower boundary ( $T_{\mathrm{s}}$ curve) was measured. More can be found in Papadakis and Bahu (1992). 
refers to the observed glass transition temperature of DDGS with $0 \%[\mathrm{db}]$ moisture, given a fixed CDS and drying temperature combination) and water in the sample, respectively; $X_{\mathrm{s}}$ and $X_{\mathrm{w}}$ are the mass fraction of solids and water (wet basis) in the sample; and $K$ is the Gordon-Taylor (1952) parameter. The value of $T_{\mathrm{gw}}$ has been experimentally determined as $-135^{\circ} \mathrm{C}$ (Gordon and Taylor 1952). For more details on how to calculate $X_{\mathrm{s}}$ and $X_{\mathrm{w}}$ for given binary system (water/solid), refer to Gordon and Taylor (1952).

The $K$ parameter, which is dependent on the $X_{\mathrm{w}}$, is different for individual materials and must be determined through regression analysis (Jaya and Das 2007).

Our goal was to create a single model for representing $T_{\mathrm{g}}=$ $f$ (drying temperature, CDS level, and moisture content) for DDGS. According to Jaya and Das (2007), $K$ is a function of $X_{\mathrm{w}}$ when moisture content is the only independent variable. However, for our samples, we had to modify $K$ to incorporate $X_{\text {w }}, \mathrm{CDS}$, and drying temperature as our independent variables. After various modifications of the base Gordon-Taylor model, we determined the modified $K$ as follows:

$$
K=\left(\mathrm{b} 1 \times X_{w}^{2}\right)+\left(\mathrm{b} 2 \times X_{w}\right)+\left(\mathrm{b} 3 \times X_{w} \times \mathrm{CDS} / T\right)
$$

Thus, the final modified Gordon-Taylor equation for this study is given as follows:

$$
T_{g}=\frac{X_{s} T_{g s}+\left(\mathrm{b} 1 X_{w}{ }^{2}+\mathrm{b} 2 X_{w}+\mathrm{b} 3 X_{w} \mathrm{CDS} / T\right) X_{w} T_{g w}}{X_{s}+\left(\mathrm{b} 1 X_{w}{ }^{2}+\mathrm{b} 2 X_{w}+\mathrm{b} 3 X_{w} \mathrm{CDS} / T\right) X_{w}}
$$

where $T_{\mathrm{g}}$ is the glass transition temperature of the mixture $\left({ }^{\circ} \mathrm{C}\right)$; $T_{\mathrm{gs}}$ and $T_{\mathrm{gw}}$ are the glass transition temperatures of the solids and water, respectively; $X_{\mathrm{s}}$ and $X_{\mathrm{w}}$ are the mass fractions of solid and water (wb), respectively; $K$ is the modified Gordon-Taylor parameter; CDS is the CDS addition level; $T$ is the drying temperature $\left({ }^{\circ} \mathrm{C}\right)$; and b1, b2, and b3 represent the model coefficients to be determined statistically from nonlinear regression.

Measurement of Sticky Point Temperature $\left(T_{s},{ }^{\circ} \mathrm{C}\right)$. Traditionally, $T_{\mathrm{s}}$ is obtained with a glass apparatus with a stirrer embedded in the sample and with a mercury seal inserted between the glass and the rod. Details on this experimental setup and associated procedures were given in Wallack and King (1988), and it was widely used for food samples (e.g., fruit powders, dairy powders, coffee powder, etc.).

For our study, we did not use the traditional experimental setup to measure $T_{\mathrm{s}}$, because of the hazardous nature of mercury, but instead developed a new approach with a rheometer (Viscoanalyzer, ATS Rheosystems, Bordentown, NJ, U.S.A.) with a cup and vane tool arrangement. The vane tool was a four-blade stirrer made of stainless steel, with a stress coefficient of $4.151 \times 10^{4}$ $\mathrm{Pa} / \mathrm{N} \cdot \mathrm{m}$, strain coefficient of $0.9261 / \mathrm{s} / \mathrm{rad}$, and inertia of $2.050 \times$ $10^{-7} \mathrm{~kg} \cdot \mathrm{mm}$. Figure 2 presents a pictorial view of the experimental setup of the rheometer and vane blade tool used to analyze $T_{\mathrm{s}}$ in this study.

The vane tool was inserted into the sample, which was regulated with a thermostat that maintained the sample at a constant set temperature from 20 to $85^{\circ} \mathrm{C}$. The shear rate increased by increments of $2.5 \times 10^{-1} 1 / \mathrm{s}$, and the temperature increased by increments of $2^{\circ} \mathrm{C}$ every $3 \mathrm{~min}$. This temperature and shear rate ramping were selected after several initial trials (data not shown). The specific temperature at which the torque (or force) showed a dramatic increase in value was identified as $T_{\mathrm{s}}$. This experimental setup was developed and used for both validation of the Wallack and King (1988) $T_{\mathrm{s}}\left({ }^{\circ} \mathrm{C}\right)$ data with coffee samples (Bhadra et al 2012a) and the DDGS in this study.

For both $T_{\mathrm{s}}$ and $T_{\mathrm{g}}$, the moisture content of the samples was controlled at 0,10 , and $20 \%(\mathrm{db})$ by adding required amounts of water and then equilibrating the samples for $24 \mathrm{~h}$ at room temperature prior to experimentation.

Experimental Design and Statistical Analyses. A full factorial design for three drying temperatures, three CDS levels, three moisture contents, and two replicate runs (thus, 54 experimental runs) was used. After all experiments were carried out, formal statistical data analyses with PROC GLM were conducted with SAS software version 8 (SAS Institute, Cary, NC, U.S.A.) and MS Excel (Microsoft, Redmond, WA, U.S.A.) to estimate regression coefficients. PROC NLIN was then performed, and TableCurve 3D version 4.0.01 (SYSTAT Software, San Jose, CA, U.S.A.) was used to develop regression equations for response surfaces.

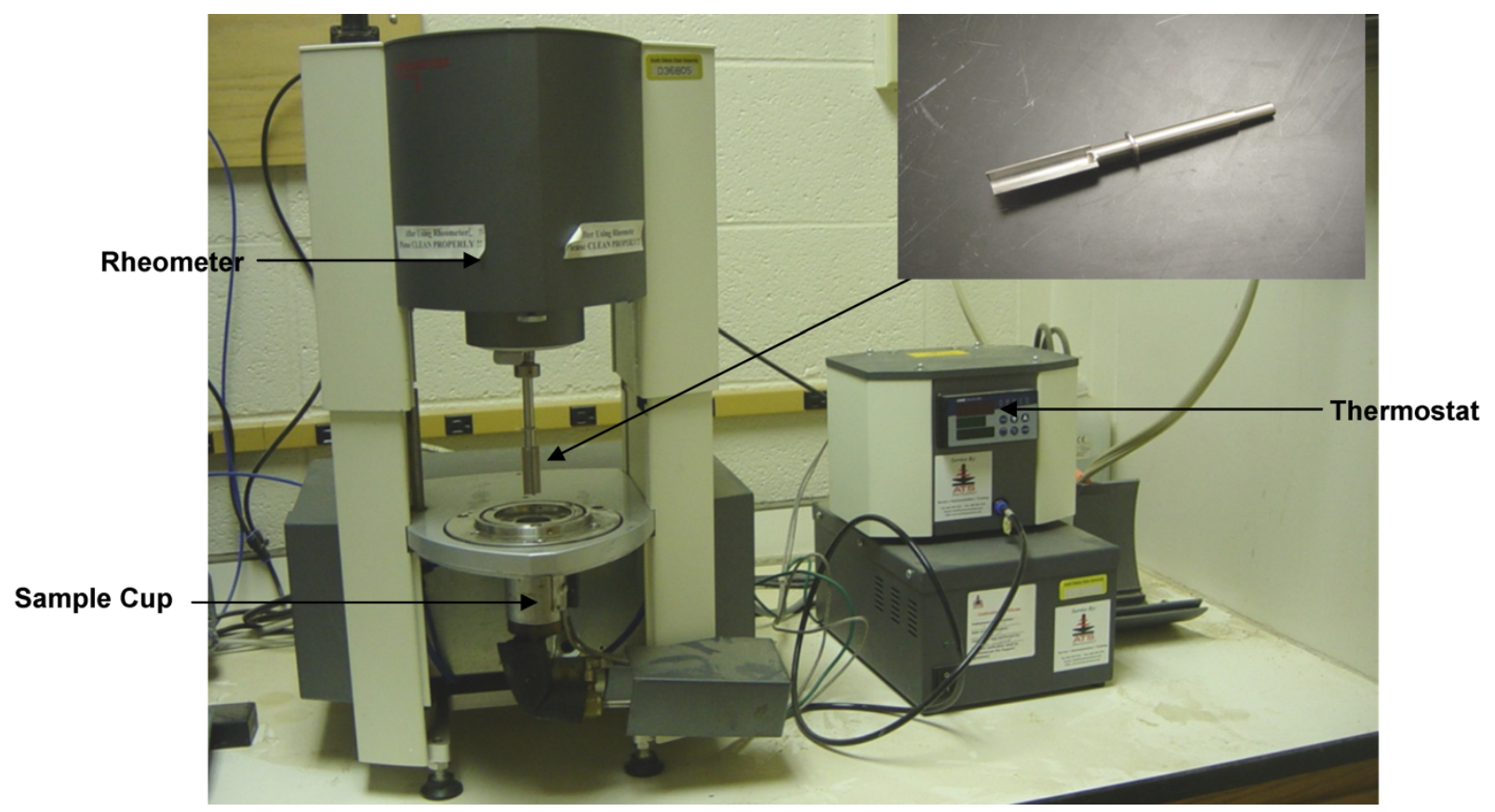

Fig. 2. Experimental setup used to measure the sticky point temperature $\left(T_{\mathrm{s}},{ }^{\circ} \mathrm{C}\right)$ using a rheometer. The four-blade vane stirring tool $(36.79 \mathrm{~mm}$ in length, $6.78 \mathrm{~mm}$ in width, and propeller shaft $105.63 \mathrm{~mm}$ in length) is enlarged in the inset. 


\section{RESULTS AND DISCUSSION}

Glass Transition Temperature Measurement and Modeling. Tables I and II illustrate the various nonlinear regression equations tried for modeling $K$ (also known as the Gordon-Taylor [1952] parameter) as a function of moisture, drying temperature, and CDS level for DDGS samples used in this study. From Table II, we can clearly see that model 11 (equation 2) yielded the highest $R^{2}$ of 0.8232 and $F$ value of 78.82 out of 24 modified equations. Even though only five modified equations showed no convergence criteria in the nonlinear modeling process, because of the lower ranges of $R^{2}$ and $F$ values we did not consider it to be possible

TABLE I

Parameter Estimates from Nonlinear Regression Modeling of $K$ as a Function of CDS, Drying Temperature, and Moisture Levels in DDGS ${ }^{\text {a }}$

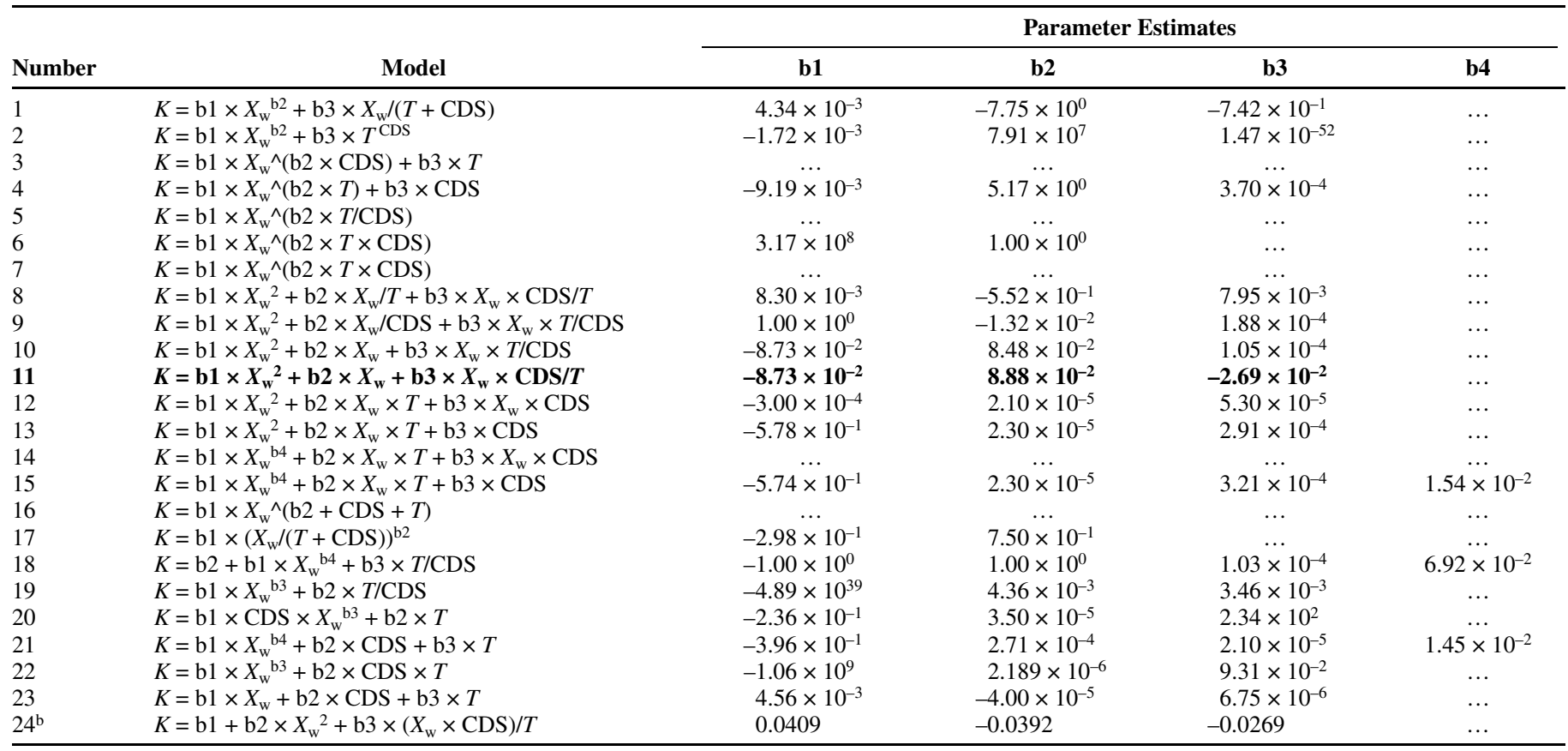

${ }^{a} K=$ the Gordon-Taylor parameter in equation $2 ; X_{\mathrm{w}}=$ the mass fraction of water (wb); CDS $=$ the condensed distillers solubles addition (\%, wb); $T=$ the drying temperature $\left({ }^{\circ} \mathrm{C}\right) ; \mathrm{b} 1, \mathrm{~b} 2, \mathrm{~b} 3$, and $\mathrm{b} 4=$ the parameter estimates of the model determined statistically; and DDGS $=$ distillers dried grains with solubles. Model 11 , indicated in bold, represents the best overall model for $K$.

$\mathrm{b}$ This is the general linear model obtained from stepwise regression procedure in SAS.

TABLE II

Model Performance of Nonlinear Regression Modeling of $K$ as a Function of CDS, Drying Temperature, and Moisture Levels in DDGS ${ }^{\text {a }}$

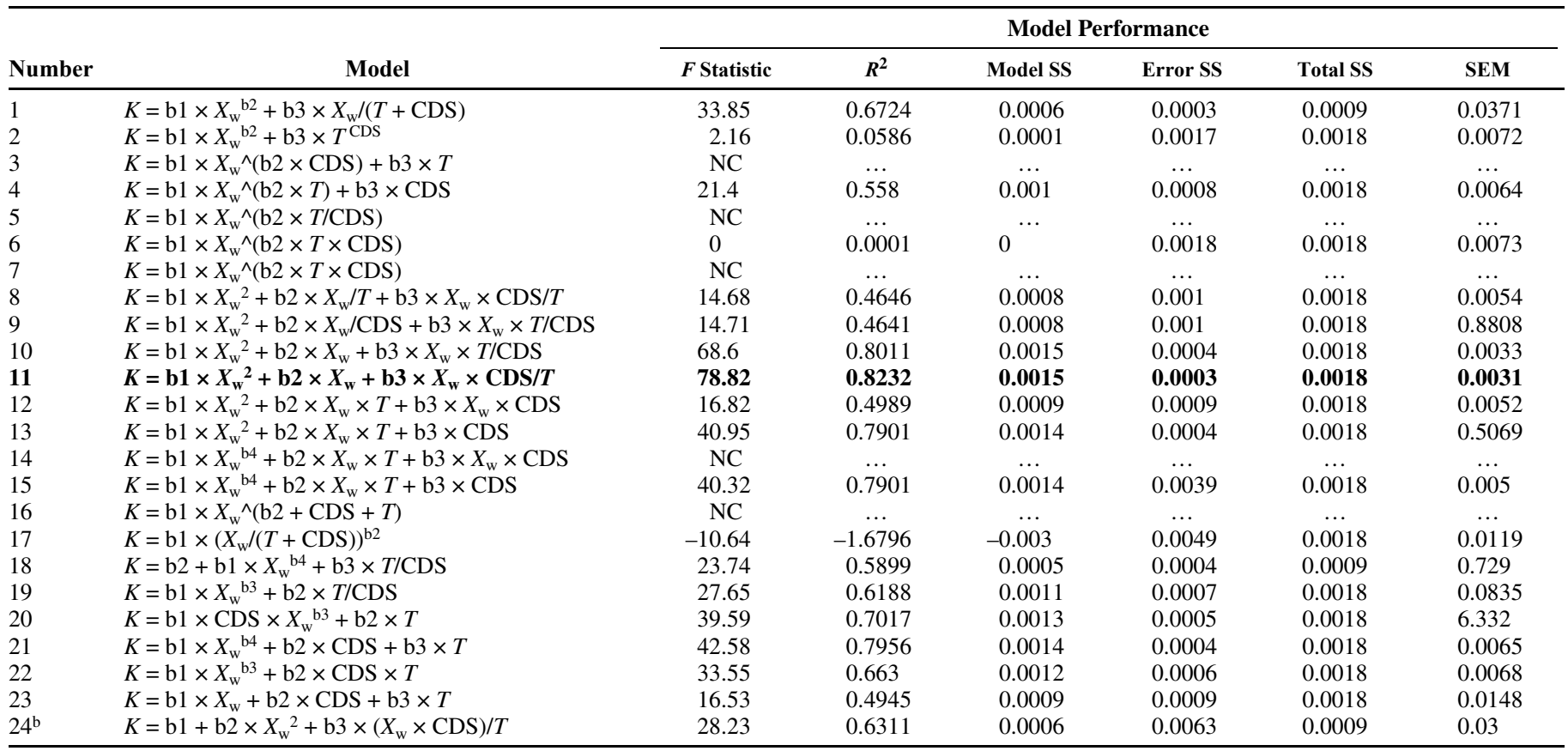

${ }^{a} K=$ the Gordon-Taylor parameter in equation $2 ; X_{\mathrm{w}}=$ the mass fraction of water (wb); CDS $=$ the condensed distillers solubles addition $(\%$, wb); $T=$ the drying temperature $\left({ }^{\circ} \mathrm{C}\right) ; \mathrm{SS}=$ sum of squares; $\mathrm{SEM}=$ the standard error of the mean; $\mathrm{NC}=$ no convergence; and DDGS = distillers dried grains with solubles. Model 11 , indicated in bold, represents the best overall model for $K$.

$\mathrm{b}$ This is the general linear model obtained from stepwise regression procedure in SAS. 
model for $K$. Convergence criteria should be met in nonlinear regression modeling (Sharma 1996). Model 24 was obtained after applying stepwise regression modeling techniques, and it yielded a lower $R^{2}$ value (0.6311) compared with the final selected nonlinear model (model 11). From Table II, we can also conclude that the standard error of the mean showed low values for most of the trial models. However, some of those were not considered as the potential model for DDGS samples with varying drying temperature, CDS, and moisture levels because they had negative predicted $K$ values and, therefore, yielded unreasonable predicted $T_{\mathrm{g}}$ values.

Previous research on $T_{\mathrm{g}}$ with various food and fruit powders predicted the $T_{\mathrm{g}}$ for varying moisture contents, but there have been no studies done (prior to this paper) that examined DDGS, specifically the effects of drying temperature, CDS, and moisture content factors on the Gordon-Taylor (1952) equation. So it was not possible to directly compare the final predicted model for $K$ (equation 2), and hence the final predicted model for $T_{\mathrm{g}}$ (equation 3 ), with previous literature. Model 11 (also equation 2) was selected as the best possible equation to predict $K$ (Gordon-Taylor parameter) for varying CDS, drying temperature, and moisture contents in DDGS. We incorporated the equation of predicted $K$ (equation 2, model 11 in Tables I and II) in the base GordonTaylor model (equation 1), which yielded the final single comprehensive model (equation 3) for predicted $T_{\mathrm{g}}\left({ }^{\circ} \mathrm{C}\right)$ with varying CDS, temperature, and moisture contents in DDGS. Research on

TABLE III

Prediction Models for $T_{\mathrm{g}}$ and $T_{\mathrm{s}}$ by Response Surface Regressiona

\begin{tabular}{llc}
\hline Parameter & Prediction of $\boldsymbol{T}_{\mathbf{g}}$ & Prediction of $\boldsymbol{T}_{\mathbf{s}}$ \\
\hline Dependent variable & & \\
$\quad z$ & Predicted $T_{\mathrm{g}}\left({ }^{\circ} \mathrm{C}\right)$ & Predicted $T_{\mathrm{s}}\left({ }^{\circ} \mathrm{C}\right)$ \\
Independent variables & & \\
$x$ & Temp $\left({ }^{\circ} \mathrm{C}\right) / \mathrm{CDS}(\% \mathrm{wb})$ & Temp $\left({ }^{\circ} \mathrm{C}\right) / \mathrm{CDS}(\% \mathrm{wb})$ \\
$y$ & Moisture content $(\% \mathrm{db})$ & Moisture content $(\% \mathrm{db})$ \\
Predicted model & $\ln z=a+b / x^{2}+c y^{0.5}$ & $\ln z=a+b / x^{2}+c y^{0.5}$ \\
Model performance & & \\
$R^{2}$ & 0.701 & 0.727 \\
Adjusted $R^{2}$ & 0.683 & 0.711 \\
$F$ statistic & 59.784 & 68.083 \\
Standard error & 3.722 & 3.766 \\
Parameter estimates & & 4.128 \\
$a$ & 4.126 & -5.573 \\
$b$ & -4.543 & -0.055 \\
$c$ & -0.051 & 6 \\
\hline Figure number & 5 & \\
\hline
\end{tabular}

${ }^{\mathrm{a}} T_{\mathrm{g}}=$ glass transition temperature $\left({ }^{\circ} \mathrm{C}\right) ; T_{\mathrm{s}}=$ sticky point temperature $\left({ }^{\circ} \mathrm{C}\right)$; Temp $=$ the drying temperature $\left({ }^{\circ} \mathrm{C}\right) ; \mathrm{CDS}=$ condensed distillers solubles addition rate $(\% \mathrm{wb})$; and $a, b$, and $c=$ parameter estimates determined statistically.

TABLE IV

Parameter Estimates for Linear Regression Modeling Between Predicted and Observed $T_{\mathrm{g}}\left({ }^{\circ} \mathrm{C}\right)$ as a Function of CDS and Drying Temperature Levels ${ }^{\mathrm{a}}$

\begin{tabular}{lccccc}
\hline $\begin{array}{l}\text { Drying } \\
\text { Temperature }\left({ }^{\circ} \mathbf{C}\right)\end{array}$ & $\begin{array}{c}\text { CDS } \\
(\boldsymbol{\%} \text { wb) }\end{array}$ & $\boldsymbol{a}$ & $\boldsymbol{b}$ & $\boldsymbol{R}^{\mathbf{2}}$ & $\mathbf{S E M}$ \\
\hline 100 & 10 & 1.4129 & -21.313 & 0.8676 & 2.47 \\
& 15 & 0.8262 & 7.7766 & 0.5470 & 2.61 \\
& 20 & 1.6663 & 33.146 & 0.9088 & 3.41 \\
200 & 10 & 0.7913 & 13.4520 & 0.9948 & 2.46 \\
& 15 & 0.5244 & 32.744 & 0.9751 & 7.30 \\
300 & 20 & 0.7202 & 18.108 & 0.8393 & 4.51 \\
& 10 & 0.5895 & 23.4300 & 0.5936 & 4.88 \\
& 15 & 0.7876 & 12.4080 & 0.7909 & 2.96 \\
& 20 & 1.0051 & -0.2785 & 0.9731 & 0.78 \\
\hline
\end{tabular}

a $T_{\mathrm{g}}=$ glass transition temperature $\left({ }^{\circ} \mathrm{C}\right) ; \mathrm{CDS}=$ condensed distillers solubles addition rate $(\% \mathrm{wb})$; predicted $T_{\mathrm{g}}$ was determined using equation 3 : predicted $T_{\mathrm{g}}=(a)\left(\right.$ observed $\left.T_{\mathrm{g}}\right)+b ;$ and $\mathrm{SEM}=$ standard error of the mean. mango, pineapple, and tomato powders by Jaya and Das (2007) was able to construct a power law type of equation for predicted $K$ parameter, but there was only moisture content as the independent variable, unlike our research design. Similar to this study, Sablani et al (2007) was able to calculate predicted $K$ and $T_{\mathrm{g}}$ values for different types of salt with low moisture contents by using the Gordon-Taylor model (1952).

A study by Bhandari et al (1997) with sugar-rich food materials mentioned clearly that the Gordon-Taylor model (1952) is best suited for a binary mixture in which one component is water and the other is a single solute. Couchman and Karasz (1978) reported for tertiary mixtures of water, sucrose, and fructose, and the equation was more complicated. For DDGS samples, we can assume it to be a binary mixture of DDGS powders and water molecules, and therefore we used the Gordon-Taylor model (equation 2) as the base model for modeling purposes.

In DDGS, we observed a nonlinear relationship with varying moisture content and $T_{\mathrm{g}}$ (Table III). As the moisture content increases, $T_{\mathrm{g}}$ decreases, which indicates more flow problems owing to possible stickiness. Similar results were found by Lloyd et al (1996) for milk powders. Roos and Karel (1991) also predicted similar effects of moisture contents on $T_{\mathrm{g}}$ values in maltodextrin. With DDGS samples prepared at different drying temperature and CDS levels, we achieved similar trends in $T_{\mathrm{g}}$ as we increased the moisture contents. Only one instance was contrary to this trend: the $T_{\mathrm{g}}$ value at $100^{\circ} \mathrm{C}$ with $20 \%$ (wb) CDS level and $20 \%$ (db) moisture content showed a slightly higher $T_{\mathrm{g}}$ value $\left(\approx 47.05^{\circ} \mathrm{C}\right)$ than $10 \%(\mathrm{db})$ moisture content $\left(\approx 43.00^{\circ} \mathrm{C}\right)$, indicating that there were less caking problem for DDGS at $20 \%$ (db) moisture content. It may be because at a lower drying temperature $\left(100^{\circ} \mathrm{C}\right)$ the highest CDS level (20\%, wb) had lubricating effects and, thus, showed slightly less cohesive problems (indicated by higher $T_{\mathrm{g}}$ ). CDS or syrups (solubles) are high in vitamins, fat, and protein but low in fiber content. Syrup also yields a digestible energy value approximately $91 \%$ of that of raw corn (Cruz et al 2005).

In this study we could analyze the individual effects of $T_{\mathrm{g}}$ on the various CDS levels and drying temperatures, and it is also stated that $T_{\mathrm{g}}$ is one of the most important factors in determining the stickiness in DDGS. More detailed kinetic studies on the viscosity and $T_{\mathrm{g}}$ in low-moisture food components, as done by Le Meste et al (2002), were not considered here. For our research design we did not consider such analysis and focused more on obtaining the overall comprehensive model for $T_{\mathrm{g}}=f($ drying temperature, CDS level, and moisture content).

In a study by Chuy and Labuza (1994) with milk powders and commercial infant formula, the $T_{\mathrm{g}}$ was predicted to have a strong linear correlation with water activity. However, for our samples, we could observe a nonlinear relationship between $T_{\mathrm{g}}$ and moisture content ( $R^{2}$ from 0.89 to 0.99 ). Moisture content and water
TABLE V

Parameter Estimates for Linear Regression Modeling Between Observed $T_{\mathrm{g}}\left({ }^{\circ} \mathrm{C}\right)$ and Observed $T_{\mathrm{s}}\left({ }^{\circ} \mathrm{C}\right)$ as a Function of CDS and Drying Temperature Levels ${ }^{\mathrm{a}}$

\begin{tabular}{lccrcc}
\hline $\begin{array}{l}\text { Drying } \\
\text { Temperature }\left({ }^{\circ} \mathbf{C}\right)\end{array}$ & $\begin{array}{c}\text { CDS } \\
(\boldsymbol{\%} \mathbf{~ w b})\end{array}$ & $\boldsymbol{a}$ & \multicolumn{1}{c}{$\boldsymbol{b}$} & $\boldsymbol{R}^{\mathbf{2}}$ & $\mathbf{S E M}$ \\
\hline 100 & 10 & 0.7216 & 14.7000 & 0.4729 & 2.17 \\
& 15 & 0.7709 & 8.8596 & 0.9836 & 2.17 \\
200 & 20 & 1.4253 & -21.3500 & 0.9324 & 2.42 \\
& 10 & 1.2280 & -9.8290 & 0.9898 & 3.24 \\
& 15 & 0.8690 & 6.3340 & 0.9896 & 1.74 \\
300 & 20 & 0.9166 & 2.6581 & 0.8511 & 3.84 \\
& 10 & 1.1337 & -9.4237 & 0.9427 & 2.77 \\
& 15 & 0.7829 & 10.1060 & 0.8284 & 2.29 \\
& 20 & 0.7615 & 11.2760 & 0.9458 & 1.86 \\
\hline
\end{tabular}

${ }^{\text {a }} T_{\mathrm{g}}=$ glass transition temperature $\left({ }^{\circ} \mathrm{C}\right) ; T_{\mathrm{s}}=$ sticky point temperature $\left({ }^{\circ} \mathrm{C}\right)$; CDS = condensed distillers solubles addition rate $(\% \mathrm{wb})$; observed $T_{\mathrm{s}}=$ (a) (observed $\left.T_{\mathrm{g}}\right)+b$; and $\mathrm{SEM}=$ standard error of the mean. 
activity are considered effective factors to measure food properties and showed high correlation $\left(R^{2}=0.969\right)$ between each other (Chirife et al 2006). Ganesan and Rosentrater (2007), the only study for $T_{\mathrm{g}}$ with DDGS (so far), predicted the range of $T_{\mathrm{g}}$ to be around $20^{\circ} \mathrm{C}$ for regular, reduced-fat, and dewaxed DDGS. Our study with DDGS samples, prepared under varying drying temperatures and CDS levels, produced a $T_{\mathrm{g}}$ range from 42 to $68^{\circ} \mathrm{C}$ and showed the trends of decreasing $T_{\mathrm{g}}$ as we increased the moisture content, indicating more flow problems and caking in the particles with higher moisture contents. In Ganesan and Rosentrater (2007), no predictive modeling for $T_{\mathrm{g}}$ (based on the Gordon-Taylor equation) as a function of moisture content, CDS, and drying temperature was done. Moreover, the $T_{\mathrm{g}}$ was reported in temperature ranges; specific $T_{\mathrm{g}}$ values were not reported in that paper.

Table IV represents the parameter estimates for predicted $T_{\mathrm{g}}$, based on our developed model (equation 3 ) versus observed $T_{\mathrm{g}}$ values. From Table IV, we can observe the $R^{2}$ values were in general above 0.79 , and many of the treatment combinations showed

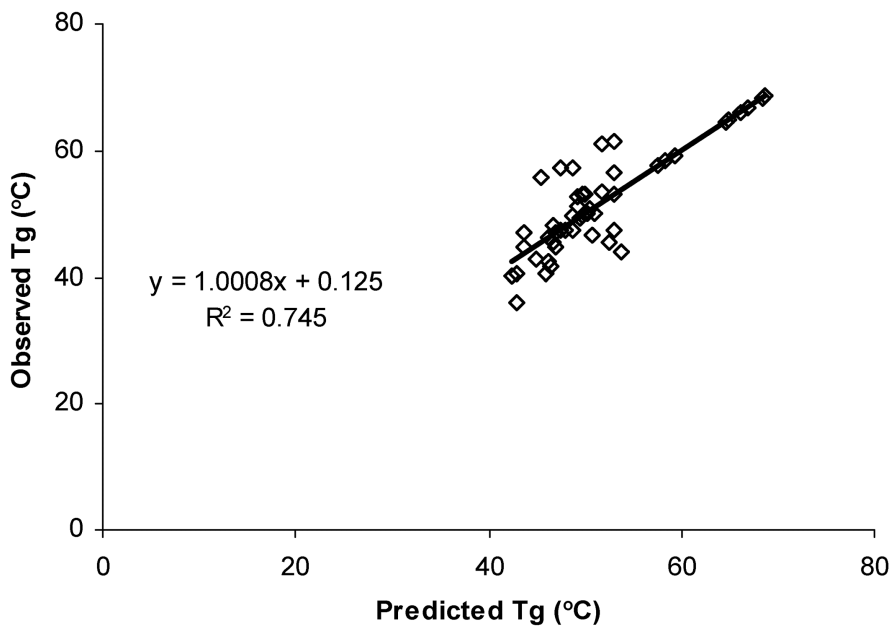

Fig. 3. Relationship between predicted $T_{\mathrm{g}}\left({ }^{\circ} \mathrm{C}\right)$ and observed $T_{\mathrm{g}}\left({ }^{\circ} \mathrm{C}\right)$ for distillers dried grains with solubles samples prepared with varying condensed distillers solubles (CDS), drying temperature, and moisture content levels, using the entire experimental data set (i.e., three CDS and three drying temperature levels).

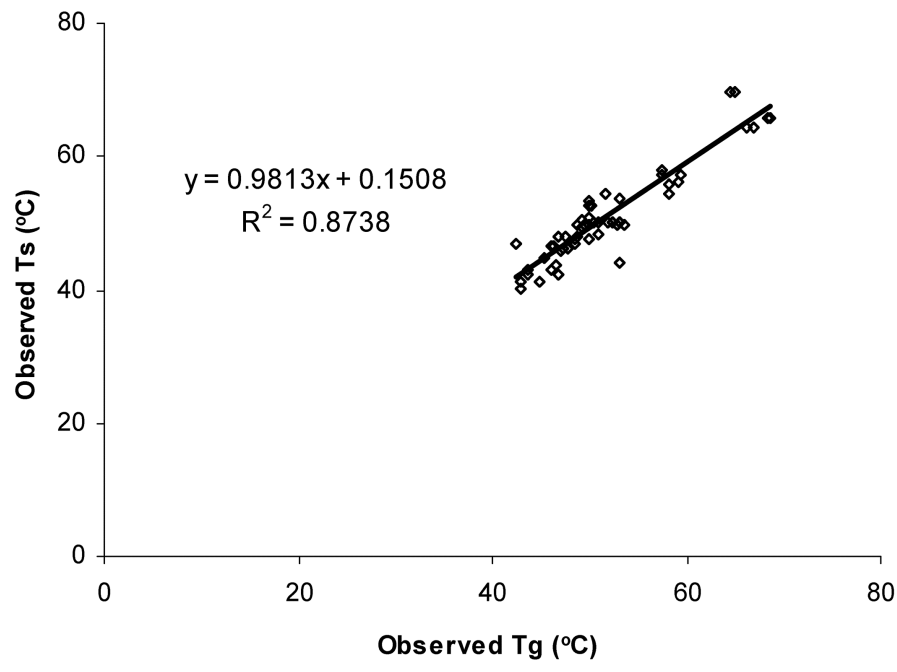

Fig. 4. Relationship between observed $T_{\mathrm{g}}\left({ }^{\circ} \mathrm{C}\right)$ and observed $T_{\mathrm{s}}\left({ }^{\circ} \mathrm{C}\right)$ for distillers dried grains with solubles samples prepared with varying condensed distillers solubles (CDS), drying temperature, and moisture content levels, using the entire experimental data set (i.e., three CDS and three drying temperature levels). higher $R^{2}$ values, indicating that our proposed model (equation 3 ) did fairly well for DDGS samples in predicting $T_{\mathrm{g}}$ values with varying CDS and drying temperature levels.

Correlation Between Glass Transition Temperature $\left(T_{\mathrm{g}},{ }^{\circ} \mathrm{C}\right)$ and Sticky Point Temperature $\left(\boldsymbol{T}_{\mathrm{s}},{ }^{\circ} \mathrm{C}\right)$. Table V represents the correlation of $T_{\mathrm{g}}$ versus $T_{\mathrm{s}}$, both popularly used to measure the stickiness, caking, or flow problems in food powders. From Table V, we can observe that except for drying temperature $100^{\circ} \mathrm{C}$ and $10 \%$ CDS levels, all the other regression coefficients were above 0.82 , indicating strong linear correlation between $T_{\mathrm{g}}$ and $T_{\mathrm{s}}$. This trend was also found in previous research with other biomaterials and fruit powders (Jaya and Das 2007; Ozmen and Langrish 2006). For DDGS, as the moisture levels increased, $T_{\mathrm{s}}$ increased, signifying higher flow problems at higher moisture levels. Similar trends in $T_{\mathrm{s}}$ values were found in coffee powders and maltodextrins (Wallack and King 1988). Also, Downton et al (1982) showed a sharp decrease in $T_{\mathrm{s}}$ as the moisture content increased for the sucrose-fructose binary amorphous mixtures.

In Werner et al (2006), corn syrup solids with different dextrose equivalents were studied, and they confirmed that $T_{\mathrm{s}}$ and $T_{\mathrm{g}}$ are

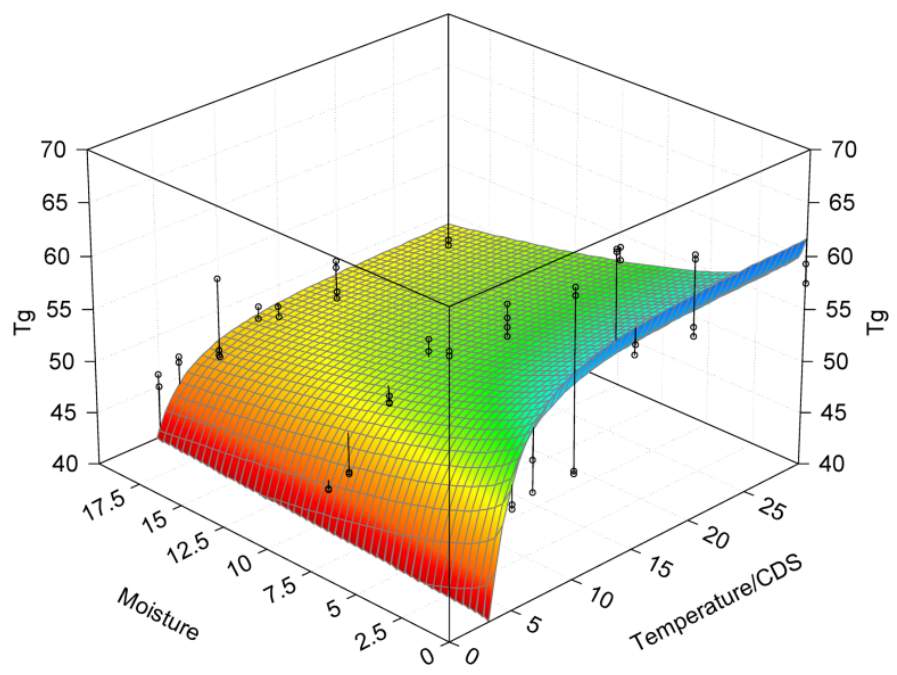

Fig. 5. Best fit response surface relationship between predicted $T_{\mathrm{g}}\left({ }^{\circ} \mathrm{C}\right)$ and condensed distillers solubles (CDS, \% wb), drying temperature $\left({ }^{\circ} \mathrm{C}\right)$, and moisture content $(\% \mathrm{db})$ levels (refer to Table III for the appropriate regression equation).

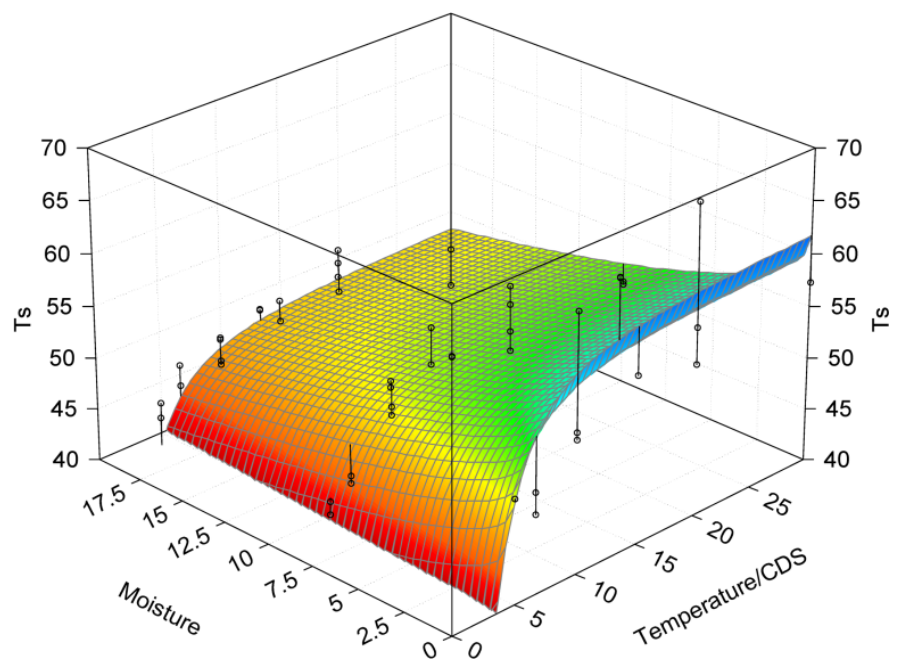

Fig. 6. Best fit response surface relationship between predicted $T_{\mathrm{s}}\left({ }^{\circ} \mathrm{C}\right)$ and condensed distillers solubles (CDS, \% wb), drying temperature $\left({ }^{\circ} \mathrm{C}\right)$, and moisture content $(\% \mathrm{db})$ levels (refer to Table III for the appropriate equation) 
closely related. Jaya and Das (2007) also showed correlation between $T_{\mathrm{g}}$ and $T_{\mathrm{s}}$ values, indicating that $T_{\mathrm{s}}$ and $T_{\mathrm{g}}$ are both similar parameters with different experimental techniques to measure them. According to Ozmen and Langrish (2006), in skim milk powder $T_{\mathrm{g}}$ and $T_{\mathrm{s}}$ were highly correlated, and they are virtually the same measurement with different experimental approaches. Our findings in Table $\mathrm{V}$ showed similar results for DDGS samples. From Table V we could observe that the $R^{2}$ for $T_{\mathrm{g}}$ versus $T_{\mathrm{s}}$ relation was above 0.85 (very favorable), and it showed a linear relationship between $T_{\mathrm{g}}$ and $T_{\mathrm{s}}$. No prior study in this context was done before, so it was not possible to compare the $R^{2}$ values of this study with relevant literature.

Figures 3 and 4 represent the overall global plots for observed $T_{\mathrm{g}}$ versus predicted $T_{\mathrm{g}}$ and observed $T_{\mathrm{g}}$ versus observed $T_{\mathrm{s}}$ for DDGS samples with varying CDS $(10,15$, and $20 \%$, wb), moisture content $(0,10$, and $20 \%, \mathrm{db})$, and drying temperature levels $\left(100,200\right.$, and $\left.300^{\circ} \mathrm{C}\right)$, respectively. We could clearly observe that the $R^{2}$ was above $\approx 0.75$ for both the cases. The $R^{2}$ value for Figure 4 (plot of observed $T_{\mathrm{g}}$ versus observed $T_{\mathrm{s}}$ ) was slightly higher (0.8738), indicating better correlation between $T_{\mathrm{s}}$ and $T_{\mathrm{g}}$. The accuracy and appropriateness of our rheometer-based approach to measure $T_{\mathrm{s}}$ for DDGS samples is discussed in detail later, in regard to the validation to determine the accuracy of the method.

Predicted $T_{\mathrm{g}}\left({ }^{\circ} \mathrm{C}\right)$ and $T_{\mathrm{s}}\left({ }^{\circ} \mathrm{C}\right)$ for Varying CDS Levels, Temperatures, and Moisture Contents. Table III illustrates the best possible nonlinear regression equation for $T_{\mathrm{g}}$ and $T_{\mathrm{s}}=f($ drying temperature, CDS level, and moisture content) with TableCurve $3 \mathrm{D}$ software. The $R^{2}$ values for both regression equations were around 0.72 . Favorable higher $R^{2}$ values $(>0.90)$ were not achieved; however, the predicted regression equations were simple and easy to implement. It could provide a vital tool for DDGS samples to predict $T_{\mathrm{g}}$ and $T_{\mathrm{s}}$ with different operating conditions in industrial applications. Figures 5 and 6 represent the corresponding response surface $3 \mathrm{D}$ plots of $T_{\mathrm{g}}=f$ (moisture content, drying temperature/CDS level) and $T_{\mathrm{s}}=f$ (moisture content, drying temperature/CDS level), respectively. Such multiple regression analyses were not previously done for DDGS samples; this study is the first of its kind that could incorporate the effects of drying temperature, CDS levels, and moisture contents simultaneously for $T_{\mathrm{g}}$ and $T_{\mathrm{s}}$ evaluation, hence predicting caking and flow problems in DDGS.

Validation of Sticky Point Temperature $\left(T_{\mathrm{s}}\right.$, $\left.{ }^{\circ} \mathrm{C}\right)$ Measurement by a Rheometer Procedure. In this study with DDGS samples, $T_{\mathrm{s}}$ was calculated with a rheometer with a vane tool and cup arrangement, as discussed in the Materials and Methods section. However, to observe the appropriateness of the $T_{\mathrm{s}}$ measurement procedure, we carried out a validation study with commercialgrade coffee powder. The original $T_{\mathrm{s}}$ data for coffee powder (reported by Wallack and King [1988]) was validated by the $T_{\mathrm{s}}$ obtained from the rheometer in the current study. Our results clearly showed that the $T_{\mathrm{s}}$ data obtained from Wallack and King (1988) for coffee powder, which used the traditional glass and tube experimental setup, and the rheometer-based $T_{\mathrm{s}}$ analysis were very close. More details on validation can be found in Bhadra et al (2012a).

\section{CONCLUSIONS}

This study determined the effect of drying temperature and CDS levels on DDGS $T_{\mathrm{g}}$ and $T_{\mathrm{s}}\left({ }^{\circ} \mathrm{C}\right)$, thus improving understanding of stickiness in DDGS particles. Similar to previous research on other biomaterials, DDGS also showed a strong correlation between $T_{\mathrm{s}}$ and $T_{\mathrm{g}}$, with $R^{2}=0.87$. Based on the Gordon-Taylor model, a global comprehensive model $\left(R^{2}=0.74\right)$ was developed for predicting $T_{\mathrm{g}}=f$ (moisture content, drying temperature, and CDS level). Stickiness in the DDGS samples increased as the moisture content increased, and it showed potential flow problems. For varying CDS levels, there were some slight changes in
$T_{\mathrm{g}}$ values: average $T_{\mathrm{g}}$ for $20 \%(\mathrm{wb}) \mathrm{CDS}\left(51.05^{\circ} \mathrm{C}\right)$ was slightly lower than average $T_{\mathrm{g}}$ for $10 \%$ (wb) $\mathrm{CDS}\left(51.81^{\circ} \mathrm{C}\right)$, indicating better flow at the $10 \%$ (wb) CDS level. Response surface regression provided nonlinear regression surfaces that can be used to predict $T_{\mathrm{s}}$ and $T_{\mathrm{g}}$ for various drying temperatures, CDS levels, and moisture contents. $T_{\mathrm{g}}$ and $T_{\mathrm{s}}$ are both considered vital parameters that quantify the stickiness and caking behavior of powders. Thus, this research is a crucial step toward understanding phase transitions and DDGS stickiness. Because no previous studies have yet examined DDGS $T_{\mathrm{s}}$ and $T_{\mathrm{g}}$, this research forms part of crucial evidence for alleviating flowability issues in DDGS, apart from flow property data analysis.

\section{ACKNOWLEDGMENTS}

The authors extend gratitude to Dakota Ethanol, LLC (Wentworth, SD), who contributed coproduct samples for this study, and to USDAARS, the South Dakota Corn Utilization Council (SDCUC), and the South Dakota Agricultural Experiment Station for providing facilities, equipment, and financial support.

\section{LITERATURE CITED}

Adhikari, B., Howes, T., Bhandari, B. R., and Truong, V. 2001. Stickiness in foods: A review of mechanisms and test methods. Int. J. Food Prop. 4(1):1-33

Bhadra, R., Muthukumarappan, K., and Rosentrater, K. A. 2009a. Flowability properties of commercial distillers dried grains with solubles (DDGS). Cereal Chem. 86:170-180.

Bhadra, R., Rosentrater, K. A., and Muthukumarappan, K. 2009b. Crosssectional staining and surface properties of DDGS particles and their influence on flowability. Cereal Chem. 86:410-420.

Bhadra, R., Muthukumarappan, K., Rosentrater, K. A., and Kannadhason, S. 2011a. Drying characteristics of distillers wet grains with varying condensed distillers solubles and drying temperature levels. Appl. Eng. Agric. 27:777-786.

Bhadra, R., Muthukumarappan, K., Rosentrater, K. A., and Kannadhason, S. 2011b. Drying kinetics of distillers wet grains (DWG) under varying condensed distillers solubles (CDS) and temperature levels. Cereal Chem. 88:451-458.

Bhadra, R., Muthukumarappan, K., and Rosentrater, K. A. 2012a. Measurement of sticky point temperature of coffee powder with rheometer. Int. J. Food Prop. 16:1071-1079.

Bhadra, R., Rosentrater, K. A., and Muthukumarappan, K. 2012b. Effects of CDS and drying temperature on the flowability behavior of DDGS. Drying Technol. 30:542-558.

Bhandari, B. R., Datta, N., and Howes, T. 1997. Problems associated with spray drying of sugar-rich foods. Drying Technol. 15:671-684.

Carr, R. L., Jr. 1965. Evaluating flow properties of solids. Chem. Eng. 72(3):163-168.

Chegini, G. R., and Ghobadian, B. 2007. Spray dryer parameters for fruit juice drying. World J. Agric. Sci. 3(2):230-236.

Chirife, J., Zamora, M. C., and Motto, A. 2006. The correlation between water activity and \% moisture in honey: Fundamental aspect and application to Argentine honeys. J. Food Eng. 72(3):287-292.

Chuy, L. E., and Labuza, T. P. 1994. Caking and stickiness of dairy-based food powders as related to glass transition. J. Food Sci. 59(1):43-46.

Couchman, P. R., and Karasz, F. F. 1978. A classical thermodynamic discussion of the effect of composition on glass transition temperatures. Macromolecules 11(1):117-119.

Cruz, C. R., Brouk, M. J., and Schingoethe, D. J. 2005. Lactational response of cows fed condensed corn distillers solubles. J. Dairy Sci. 88:4000-4006.

Downton, G. E., Flores-Luna, J. L., and King, C. J. 1982. Mechanism of stickiness in hygroscopic, amorphous powders. Ind. Eng. Chem. Fundam. 21(3):447-451.

Ganesan, V., and Rosentrater, K. A. 2007. Characterization of DDGS using differential scanning calorimetry. In: CSBE/ASABE North Central Intersectional Conference, 12-13 October, Fargo, ND. Paper No. RRV-07147. St. Joseph, MI: ASABE.

Ganesan, V., Rosentrater, K. A., and Muthukumarappan, K. 2007a. Modeling the flow properties of DDGS. Cereal Chem. 84:556-562.

Ganesan, V., Rosentrater, K. A., and Muthukumarappan, K. 2007b. Physi- 
cal and flow properties of regular and reduced fat distillers dried grains with solubles (DDGS). Food Bioproc. Technol. 2(2):156-166.

Ganesan, V., Muthukumarappan, K., and Rosentrater, K. A. 2008a. Effect of flow agent addition on physical properties of DDGS with varying moisture contents and soluble percentages. Trans. ASABE 51(2):591601.

Ganesan, V., Muthukumarappan, K., and Rosentrater, K. A. 2008b. Flow properties of DDGS with varying soluble and moisture content using Jenike shear testing. J. Powder Technol. 187(2):130-137.

Gordon, M., and Taylor, J. S. 1952. Ideal copolymers and second-order transition of synthetic rubbers. I. Non-crystalline co-polymers. J. Appl. Chem. 2:493-500.

Hegg, P. H., Castberg, H. B., and Lundh, G. 1985. Fouling of whey proteins on stainless steel at different temperatures. J. Dairy Res. 52(1):231-218.

Hennigs, C., Kockel, T. K., and Langrish, T. A. G. 2001. New measurements of sticky behavior of skim milk. Drying Technol. 19:471-484.

Jaya, S., and Das, H. 2007. Glass transition and sticky point temperatures and stability/mobility diagrams of fruit powders. Food Bioproc. Technol. 2(1):89-95.

Jenike, A. W. 1964. Storage and flow of solids. Bulletin No. 123. Utah Engineering Station, University of Utah: Salt Lake City, UT.

Kudra, T. 2003. Sticky region in drying-Definition and identification. Drying Technol. 21:1457-1469.

Lazar, M. E., Brown, A. H., Smith, G. S., Wong, F. F., and Lindquist, F. E. 1956. Experimental production of tomato powder by spray drying. Food Technol. 3(1):129-134.

Le Meste, M., Champion, D., Roudaut, G., Blond, G., and Simatos, D. 2002. Glass transition and food technology: A critical appraisal. J. Food Sci. 67(7):2444-2458.

Lloyd, R. J., Chen, X. D., and Hargreaves, J. B. 1996. Glass transition and caking of spray-dried lactose. Int. J. Food Sci. 31(4):305-311.

Netto, F. M., Desobry, S. A., and Labuza, T. P. 1998. Effect of water content on the glass transition temperature, caking, and stickiness of protein hydrolysates. Int. J. Food Prop. 1(2):141-161.

Ozmen, L., and Langrish, T. A. G. 2006. Comparison of glass transition temperature and sticky point temperature for skim milk powder. Drying Technol. 20:1177-1192.
Papadakis, S. E., and Bahu, R. E. 1992. The sticky issues of drying. Drying Technol. 10:817-837.

Pasley, H., Haloulos, P., and Ledig, S. 1995. Stickiness-A comparison of test methods and characterization parameters. Drying Technol. 13:1587-1601.

Rock, M., and Schwedes, J. 2005. Investigations on the caking behavior of bulk solids-Macroscale experiments. Powder Technol. 157:121-127.

Roos, Y. H., and Karel, M. 1990. Differential scanning calorimetry study of phase transitions affecting the quality of dehydrated materials. Biotechnol. Prog. 6:159-163.

Roos, Y. H., and Karel, M. 1991. Phase transitions of mixtures of amorphous polysaccharides and sugars. Biotechnol. Prog. 7:49-53.

Rosentrater, K. A., and Muthukumarappan, K. 2006. Corn ethanol coproducts: Generation, properties, and future prospects. Int. Sugar J. 108(1295):648-657.

Sablani, S. S., Kasapis, S., and Rahman, M. S. 2007. Evaluating water activity and glass transition concepts for food stability. J. Food Eng. 78:266-271.

Sharma, S. 1996. Applied Multivariate Techniques, 1st Ed. Wiley: New York, NY.

Simatos, D., and Blond, D. 1993. Some aspects of the glass transition in frozen food systems. Pages 395-416 in: The Glassy State in Foods. J. M. V. Blanshard and P. J. Liliford, eds. Nottingham University Press: Leicestershire, U.K.

Speihs, M. J., Whitney, M. H., and Shurson, G. C. 2002. Nutrient database for distiller's dried grains with solubles produced from new ethanol plants in Minnesota and South Dakota. J. Anim. Sci. 80:2639-2645.

Teunou, E., Fitzpatrick, J. J., and Synnott, E. C. 1999. Characterization of food powder flowability. J. Food Eng. 39(1):31-37.

Wallack, D., and King, C. J. 1988. Sticking and agglomeration of hydroscopic, amorphous carbohydrate and food powders. Biotechnol. Prog. $4: 31-34$.

Werner, S. R. L., Franshawe, R. L., Paterson, A. H. J., Jones, J. R., and Pearce, D. L. 2006. Stickiness of corn syrup powders by fluidized bed test. Int. J. Food Eng. 2(5):1-10.

Williams, M. L., Landel, R. F., and Ferry, J. D. 1955. The temperature dependence of relaxation mechanisms in amorphous polymers and other glass forming liquids. J. Am. Chem. Soc. 77:3701-3707.

[Received May 30, 2013. Accepted January 28, 2014.] 